\title{
Disc brake squeal characterization through simplified test rigs
}

\author{
A. Akay ${ }^{c, 1}$, O. Giannini ${ }^{\mathrm{a}, *}$, F. Massi ${ }^{\mathrm{a}, \mathrm{b}}$, A. Sestieri ${ }^{\mathrm{a}}$ \\ a Dipartimento di Meccanica e Aeronautica (DMA), University of Rome "la Sapienza", Italy \\ b Université de Lyon, CNRS INSA-Lyon, LaMCOS UMR5259, F-69621, Villeurbanne, France \\ c Bilkent University, 06800 Bilkent, Ankara, Turkey
}

\section{A R T I C L E I N F O}

\section{Article history:}

Received 17 December 2007

Received in revised form

11 March 2009

Accepted 16 March 2009

Available online 10 April 2009

\section{Keywords:}

Brake squeal noise

Experimental test rig

Damping

Mode lock-in

Instability

\begin{abstract}
A B S T R A C T
This paper presents a review of recent investigations on brake squeal noise carried out on simplified experimental rigs. The common theme of these works is that of approaching the study of squeal noise on experimental set-ups that are much simpler than commercial disc brakes, providing the possibility of repeatable measurements of squeal occurrence. As a consequence, it is possible to build consistent and robust models of the experimental apparatus to simulate the squeal events and to understand the physics behind squeal instabilities.
\end{abstract}

(C) 2009 Published by Elsevier Ltd.

\section{Introduction}

Brake squeal is a very complex phenomenon, and its investigation requires expertise from different disciplines [1] (e.g. vibrations, tribology, acoustics, etc.) as evidenced by the variety of approaches to the problem and the variety of explanations on how brake squeal originates that have been proposed so far. However, there is yet neither a complete understanding of the problem nor a generalized theory of squeal mechanism.

It is generally considered that one of the main difficulties encountered in studying brake squeal is the high complexity of a brake system. Such complexity, together with the ever-present data dispersion in experimental studies, is one of the main reasons that does not permit yet an efficient control of brake squeal noise.

Traditionally, research groups working on this subject conducted their investigations by combining theory and experiments. Many such studies started by conducting experiments on simplified test rigs, trying to correlate the experimental results with theoretical models. The aim of these approaches was primarily to acquire a clear understanding of the squeal mechanisms and then to extend such knowledge to build increasingly complex models and, finally, to control the squeal occurrence in commercial brakes.

An extensive review of most classical studies on brake squeal can be found in Kinkaid et al. [2]. This paper presents an overview of studies carried out in a collaborative effort among the Department of Mechanics and Aeronautics in Rome (DMA), Carnegie Mellon University in Pittsburgh, PA (CMU), and LaMCoS in Lyon on simplified experimental rigs developed through the years, highlighting the main findings and the proposed modelling ideas.

\footnotetext{
* Corresponding author.

E-mail address: Oliviero.giannini@uniroma1.it (O. Giannini).

${ }^{1}$ on leave from Carnegie Mellon University, Pittsburgh, PA, USA.
} 
Three set-ups, developed to simulate the dynamics of the system and to predict the squeal occurrence, together with their corresponding models, are discussed in this paper: the beam on disc, the Laboratory Brake, and the TriboBrake CORLIS.

The obtained experimental evidences allow for a comprehensive understanding of the squeal phenomenon and provide a useful basis necessary to approach successfully a "squeal free" design of brakes.

\section{Simplified experimental set-up}

\subsection{Motivations}

The complexity of commercial brakes represents a major difficulty in investigating squeal noise. In fact the automotive brakes are mass produced systems and have several parts whose dynamic characteristics may vary widely due to wear, assembly process, and other inherent uncertainties.

As a result, from an experimental point of view, it is generally difficult to perform repeatable measurements; from a modelling point of view, it is not trivial to reproduce consistently the dynamic behaviour of the brake, especially with regard to the pad-caliper assembly.

In part, for these reasons there is not yet a complete understanding of the squeal mechanism so that many research groups focused their studies on simplified rigs. In fact, working with simplified experimental set-ups has several advantages that can be summarized as follows.

Simplified geometry. Two major advantages arise from an easy geometry of the set-up and, thus, a simple model of the system: (i) it allows for more consistent models and reduces the uncertainties related to complicated set-ups and (ii) it permits more repeatable measurements.

Small contact area between the disc and the pad. This is the primary common characteristic of all the simplified set-ups considered in this paper. A small contact area leads to weak coupling between the rotor and the caliper so that it is possible to describe the coupled dynamics of the system in terms of the dynamics of each component. This is certainly a characteristic not encountered in real brakes; however, it permits a clear, even if not exhaustive, exploration of the squeal mechanism.

Dedicated design of the experimental rig. Each simplified set-up is devoted to understand a specific aspect of the squeal mechanism. As a consequence, it is possible to eliminate all the functional parts that are necessary in a commercial brake but are not relevant for the study of that aspect of the squeal development. This makes the system much simpler, allowing for repeatable measurements with controllable parameters.

Insertion of sensors. Related to the previous aspect, the design of the experimental rig is optimized for the insertion of appropriate sensors, allowing direct measurement of the parameters of interest.

All of the set-ups considered here share these common characteristics and, as a result, they are easily controllable, able to provide repeatable measurements and provide the possibility to isolate a specific aspect of squeal from the others.

The drawback of such simplification is that the study is no longer conducted on a real brake system. A common argument against simplified set-ups is that important aspects that can lead to instability are neglected in the design so that the results cannot be wholly generalized to brake squeal occurring in commercial brakes.

While these concerns have merit, benefits of simplified test rigs can be summarized as follows:

1. The simplified set-up may not be able to reproduce consistently all the causes of squeal, but certainly reproduces some.

2. The simplified experimental rigs can be used as benchmarks to test the validity of the models. In fact, a model that does not provide results consistent with the experiments obtained from the simplified set-up would definitely not be adequate for real brake (even if the contrary may be not true).

3. If experimentation on commercial brakes highlights squeal events that are not reproduced by simplified set-ups, it is always possible to design an appropriate simplified rig to reproduce and study that specific squeal event.

4. Finally, from a modelling point of view, simple test rigs can be better described by models where the influence of each parameter is well understood and can be appropriately taken into account. On the contrary, real brakes can be modelled only by finite elements (FEs). Since the squeal problem is not yet completely understood, it is quite difficult to create a valid FE model of the brake and, especially, to have a significant control of the key parameters such as in- and out-ofplane stiffness of the pad, contact stiffness, modal damping of the brake components, and pressure distribution between disc and pad.

\subsection{The beam-on-disc set-up}

The beam on disc is a development of the pin on disc proposed by Earles and Soar [3] and Earles [4] in the 1960s.

The beam-on-disc consists of a cantilever beam (representing the brake pad) and a rotating disc (the disc brake rotor) pressed against each other by a dead weight. The geometry of both the disc and the beam as well as the materials change depending on the specific realization of the set-up. Fig. 1 shows a schematic of the beam-on-disc set-up. The angle of 
incidence of the beam and its length are adjustable. The cantilever beam is mounted on a sliding platform that moves on two linear bearings, allowing the cantilever beam to be pre-loaded against the disc with a specified normal load. The main difference of this set-up with respect to the pin-on-disc is the beam flexibility, which introduces a coupling between the dynamics of two bodies and introduces unstable conditions. The beam on disc was proposed by Akay [5], and later used, with the same basic geometry, by Tuchinda et al. [6,7], Allgaier et al. [8], Allgaier [9], and Giannini and Massi [10]. This setup is able to capture and analyze the mode lock-in phenomenon, which is discussed in Section 3.1.

\subsection{The laboratory brake set-up}

The laboratory brake [11-18] (Fig. 2) is designed to be the "trait d'union" between the beam on disc and a commercial brake. In fact, the laboratory brake is an experimental rig designed, on one hand, to be a reliable set-up able to produce squeal in a controlled and reproducible way and, on the other hand, to represent a commercial brake as closely as possible.

The experimental set-up consists of a disc mounted on a rotating shaft, and constrained between a pair of beams that represent the caliper, and two small brake pads. The pads were obtained by machining commercial pads, which are pressed against the disc.

Depending on the specific realization of the set-up, the physical dimensions, as well as the transmission line can be different. Moreover, the dimensions of the pad can be changed: in [11-14,16,17] a small brake pad is used, in [15,18] two small brake pads are mounted on each beam. Also the shape of the disc may change and can be either a machined disc or a commercial brake disc.

With respect to the beam-on-disc set-up [5-9], the laboratory brake is characterized by three major improvements that make this set-up much closer to a real brake:

- The materials in contact are analogous to a real brake pair.

- The coupling between the out-of-plane vibrations of the disc and its in-plane motion is far less strong and much closer to a real brake. In fact, in the beam-on-disc the angle between the beam and the disc is close to $45^{\circ}$. This allows the friction force to excite easily the bending vibrations of the beam. These vibrations have a consistent component in the out-of-plane direction and can, thus, excite back the disc. The laboratory brake has two beams (representing the caliper) that are almost parallel to the disc plane and, thus, a geometry much closer to that of a real brake, characterized by a weak geometric coupling between in- and out-of-plane vibrations.

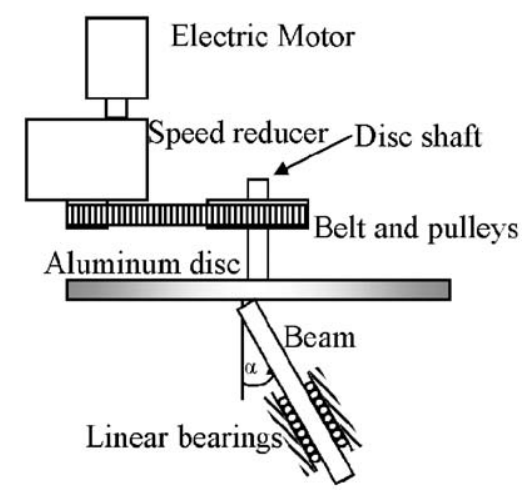

Fig. 1. Schematic of the beam-on-disc set-up.

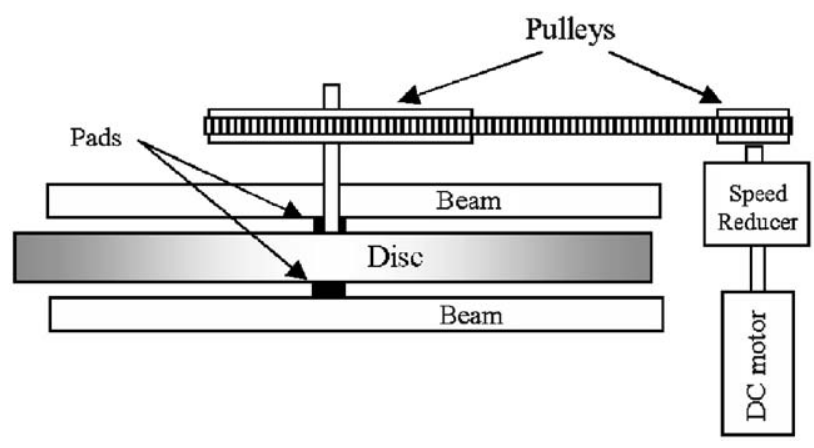

Fig. 2. Scheme of the laboratory brake. 


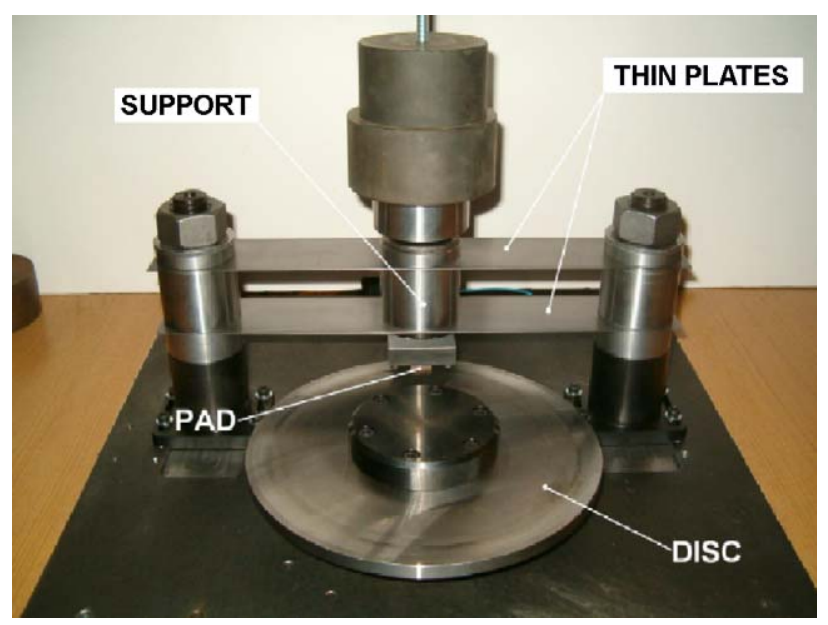

Fig. 3. The TriboBrake COLRIS.

- The beam-on-disc is characterized by two structures with low damping interacting through friction force. In the laboratory brake, on the contrary, the brake pads have a high damping loss factor (the measurements indicate a $6 \%$ loss factor), which affects the modal interaction, leading to instability.

\subsection{The tribobrake}

The tribobrake COllaboration Lyon-Rome for Investigation on Squeal (COLRIS) was designed to model the dynamics of the brake system and to conduct tribological analysis of contact surfaces, with the aim of correlating the dynamic and tribological aspects of squeal. In contrats to the approaches to the problem that have been mostly confined either to a dynamic analysis [3-23] or to tribological studies (analysis of the contact surfaces) [24-30], the work on this experimental rig has been combined overview of the phenomena [31-33].

The tribobrake was designed to be modelled using both linear and nonlinear FE models, in order to predict the squeal events and analyze the behaviour of the system in the time domain.

The set-up consists of a rotating disc and a small friction pad pressed against the disc by weighs on a support (Fig. 3). The brake pads are made of commercial brake friction material. Reduced pad dimensions are used to simplify and control with ease the dynamics of the pad by changing its dimensions. The floating support (the middle cylindrical body held by two thin plates) is designed to represent a simplified caliper. The friction pad is attached to the support through a back-plate, so that it can be disassembled for a tribological analysis of the contact surfaces.

The tribobrake presents the following characteristics that distinguish it from the previous simplified rigs:

The caliper is represented by the cylindrical support that has a clearly identifiable in-plane dynamics. This permits us to distinguish the in-plane dynamics of the pad from the dynamics of the support;

a tri-axial force transducer between the pad and the support permits recording of the time histories of the normal and friction forces, allows comparison between the experiments and the nonlinear transient analysis performed on the model, ${ }^{2}$

\section{Experimental results}

In this section, the main findings obtained through the investigations carried out on the simplified rigs are presented and linked together to provide a clear view of the squeal instability as it develops in such systems.

- The first almost obvious observation is that squeal is the consequence of friction-induced vibration. However, the most important result observed by all the proposed set-ups, but specifically met for the first time in the experiments with beam on disc is the consistent strong correlation between squeal occurrence and mode lock-in between two modes of the pad, disc, or calliper subsystems. Usually the modes involved are stationary, i.e. the deformed shape and the nodal lines do not rotate with the disc and are fixed with respect to the pad.

\footnotetext{
${ }^{2}$ In the beam on disc and in the laboratory brake, only the mean value of the normal force was directly measured.
} 
- The presence of rotating squeal can be observed under particular conditions, as clearly observed on the laboratory brake.

- Absence of stick-slip during squeal instability.

- The evidence that the sound pressure amplitude is not sensitive to speed variations of the disc beyond a certain value. At low speed, however, the pressure amplitude decreases with decreasing rotational speed of the disc.

- The modal damping can have a significant influence on squeal propensity.

- The characteristic topography of the contact surface of the disc, observed on the tribobrake by means of a scanning electron microscope (SEM), reveals fatigue phenomena due to local force oscillations.

Some of these results are now well known, but they were all observed on the proposed simplified test rigs and are particularly important to model the squeal mechanism.

\subsection{The squeal mechanisms and mode lock-in}

Four different mechanisms that lead a brake system to unstable behaviour are considered as possible causes of brake squeal noise.

- Early works on the brake squeal problem (e.g. Mills [34]) considered that a necessary condition for the onset of an unstable behaviour of a squealing brake is negative damping arising from a $\mu-v_{\mathrm{r}}$ decreasing characteristic, where $\mu$ is the friction coefficient and $v_{\mathrm{r}}$ the relative velocity between rotor and pads.

- The sprag-slip instability was introduced by Spurr [35] in 1961, which is the first squeal model compatible with a constant friction coefficient.

- Instability of parametric resonances at speed below the critical speeds, as shown among others by Chan et al. [36].

- The mode lock-in instability, ${ }^{3}$ which is nowadays the most widely considered cause of brake squeal noise, will be further explained.

The instability that develops in dynamic models when two eigenfrequencies of the system, due to the asymmetry of the stiffness matrix, coalesce and become unstable, is now known as mode lock-in as the term was coined by Akay in [5]. The idea of the coupling mechanism for the squeal occurrence was first introduced by North [19,20] in 1972. North proposed a two-degrees of freedom (dof) system, characterized by an asymmetric stiffness matrix, due to the presence of friction forces, the friction coefficient being constant.

Fig. 4 shows the results of the complex eigenvalue analysis for the two-dof model proposed by North in [20] ${ }^{4}$; the graph on the left shows that, as $k_{1}$ increases, the first eigenfrequency of the undamped system (the translational degree of freedom) also increases. Once the two eigenvalues approach each other, they coalesce and the system becomes unstable. The coalescence point is called the mode lock-in point. The right-hand graph shows the same results in the locus plot, with the effective percent damping on the $x$-axis and the frequency of the eigenvalues on the $y$-axis. The two eigenvalues move toward each other along the zero-damping axis (imaginary axis). When they reach the lock-in point they coalesce and become conjugates of each other. One eigenvalue moves toward the negative damping semi-plane (positive real part of the eigenvalue), while the other moves to the positive damping semi-plane. The negative effective damping is related to the squeal unstable behaviour. In [10] Massi and Giannini present the first experimental lock-in plot obtained using the beamon-disc set-up.

\subsection{Mode lock-in characterization}

The squeal tests performed using the beam-on-disc apparatus were designed to search for repeatable squeal conditions by varying the length of the beam, the angle between the disc and the beam, and the normal load. Fig. 5 summarizes the main results obtained with the beam on disc: the vertical lines are the natural frequencies of the disc alone, the transverse curves the natural frequencies of the beam as a function of the beam length (vertical axes), and the black dots are the squeal frequencies obtained during the experiment.

The results show that, in general, squeal occurs near the disc or the beam natural frequencies, when they are close to each other.

Moreover, all squeal conditions measured during the tests involve a cosine mode of the disc, i.e. a mode with an antinode at the contact point, also referred to as a $(n, m+)$ mode. ${ }^{5}$

The test performed using the laboratory brake confirmed the lock-in theory on a more complex system. In fact, the squeal frequency can be easily related to the dynamics of the system. Fig. 6 shows the frequency response function of the

\footnotetext{
${ }^{3}$ Also known as: modal coupling instability or binary flutter instability

${ }^{4}$ Numerical parameters used for calculation are in MKS units: $m=1, J=2, k_{\mathrm{t}}=100,300<k_{1}=k_{2}<500, \mu=0.5, h=0.01, N_{0}=100, L=0.1$, $k_{\mathrm{r}}=1000$.

${ }^{5}$ Due to the asymmetry introduced by the contact, the double modes of the disc split at two different frequencies, becoming the sine ( $n, m-$ ) and the cosine $(n, m+)$ modes, $n$ and $m$ being the numbers of nodal circumferences and nodal diameters, respectively.
} 
a

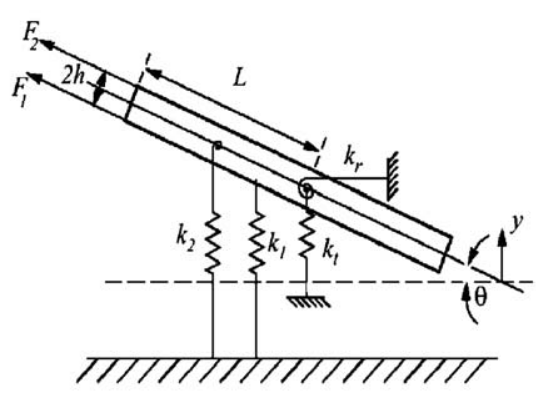

b

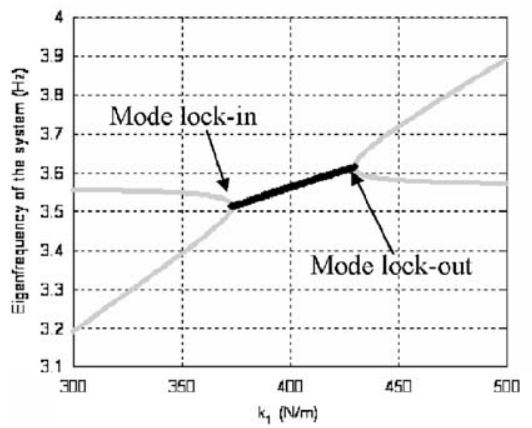

C

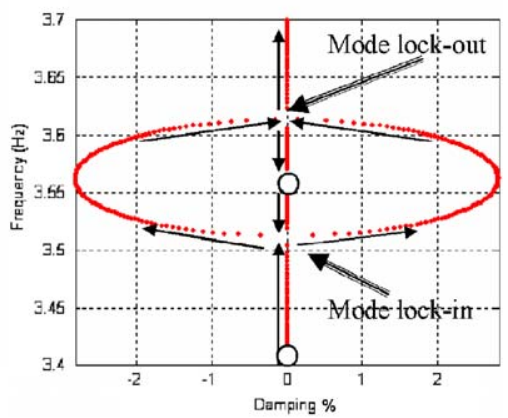

Fig. 4. Complex eigenvalue analysis of the North 2DoF model. (a) Schematic of North's two-dof model, (b) lock-in plot, and (c) root behaviour in the locus plot.

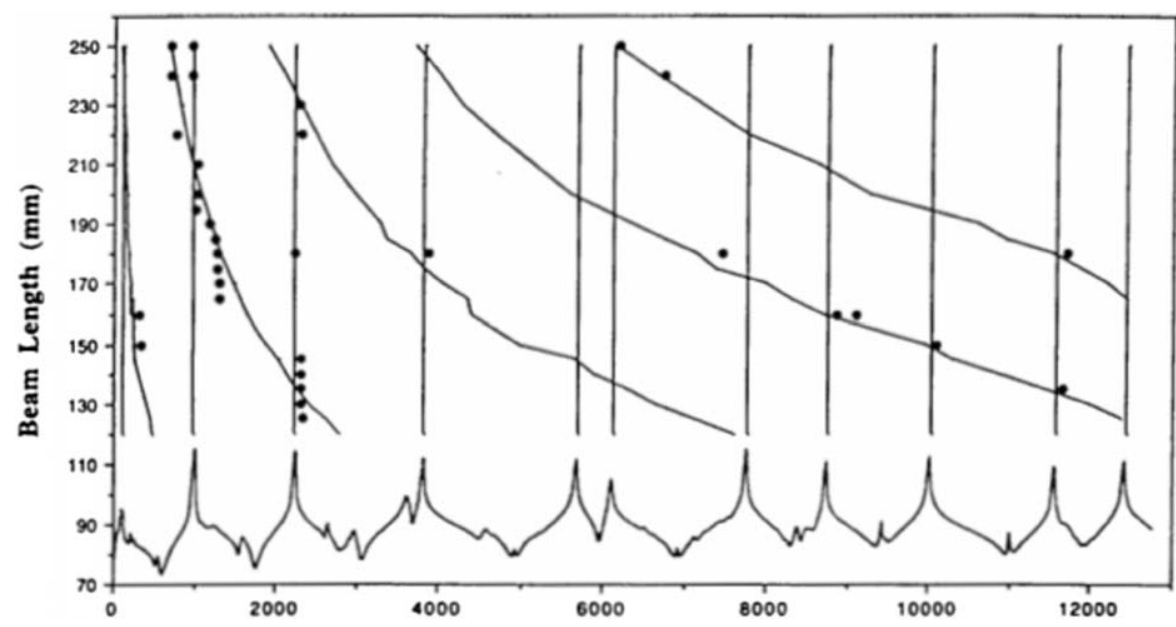

Fig. 5. Beam-on-disc mode lock-in (Akay et al. [5]).

laboratory brake and the squeal occurrences when small brake pads are used $\left(1 \mathrm{~cm}^{2}\right.$ contact area). As in the beam-on-disc, squeal involves the cosine modes of the disc, but it can also occur at frequencies corresponding to the beam modes.

In the beam on disc and in the laboratory brake, squeal always involves a bending mode of the rotor and never an inplane mode. This is mainly due to the fact that the used rotors in these set-ups are flat discs, missing the hat structure. The hat structure of a commercial brake rotor couples in-plane modes with out-of-plane modes; for this reason the formers may lead to a squealing behaviour. If the laboratory brakes accommodate a commercial rotor, such as in [37], in-plane modes can indeed participate in squeal.

Moreover, the squeal frequency is always coincident with a natural frequency of the coupled system and not with the frequency of the free rotor (this explains the small discrepancy between squeal frequency and free rotor natural frequency in Fig. 5).

The laboratory brake is characterized by a larger coupling between disc and beam dynamics with respect to the beamon-disc. For this reason, it is possible to clearly see that the squeal frequencies correspond to modes of the coupled system and not to the natural frequency of the free rotor (usually $50 \mathrm{~Hz}$ below the squeal frequency). ${ }^{6}$

The experimental analyses performed on the tribobrake also confirm the lock-in theory; in fact, in the dynamics of the assembled system it is possible to recognize the combined response of the disc and the support. A further analysis on this set-up shows also the influence of the pad on the dynamics on the assembled system [31,33]. Both the pad and the support present tangential vibration modes along the contact surface. The experiments show that a mode of one subsystem characterized by normal vibration at the contact zone can couple with a mode of the other subsystem characterized by

\footnotetext{
${ }^{6}$ The free rotor natural frequencies are measured with the pad not in contact with the disc, while the disc is stationary and constrained on the shaft. The coupled natural frequencies are measured with the pad engaged on the disc, which remains stationary.
} 


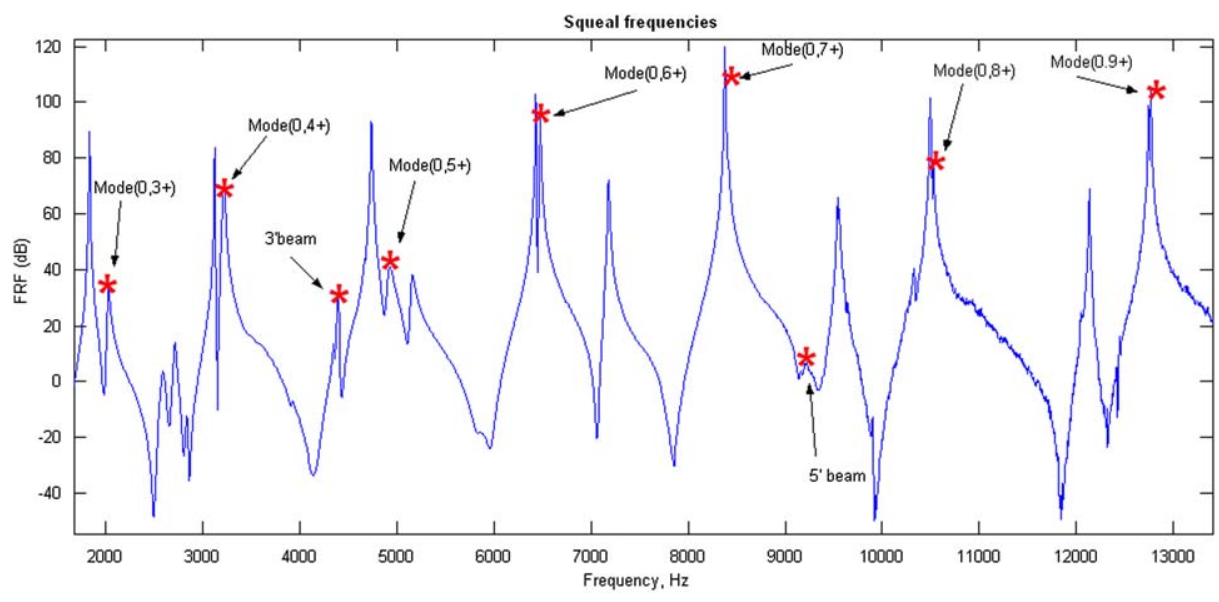

Fig. 6. FRF of the coupled system and squeal frequencies (stars).

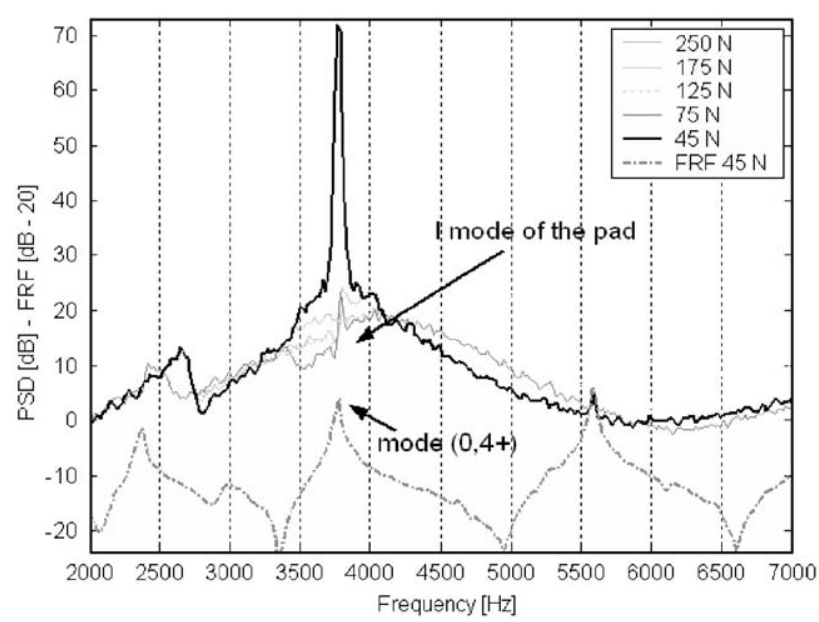

Fig. 7. Dynamic characterization of the system for squeal coupling.

tangential vibration at the contact. This means that an effective "squeal-free" design should take into account both the pad and the caliper interaction with the disc.

Moreover, the use of the tribobrake highlights the importance of the in-plane dynamics of either the pad or the support in the squealing mode selection mechanism. Fig. 7 presents a dynamic characterization of the pad when squeal occurs at $3767 \mathrm{~Hz}$; the grey lines are the power spectral density (PSD) of the pad acceleration in the tangential direction for values of the normal load ranging from 45 to $250 \mathrm{~N}$, while the dashed line is the measured FRF of the disc. By lowering the normal load, the first mode of the pad moves to lower frequencies and approaches the $(0,4+)$ mode of the disc. Sequel develops only when the pad natural frequency is close enough to the disc natural frequency ; this is called a "tuning in" condition. ${ }^{7}$

Fig. 8 shows the disc modes involved in squeal events during experiments, along with the frequency ranges covered by the support and the pad modes when changing the driving parameters.

The modes $\left(0, \mathrm{~m}^{+}\right)$of the disc that fall in the range of frequencies covered by the support and pad modes may be involved in instability and become unstable when their frequencies lock-in with the corresponding ones of support or pad modes.

The modes of the rotor, such as the $(0,5+)$ mode, that are outside these ranges, do not squeal during experiments.

\subsection{Rotating squeal}

The laboratory brake was also used to investigate high-frequency squeals. When two small brake pads are mounted on the same beam, at a distance $d$ apart a quite different behaviour develops [15,18].

\footnotetext{
${ }^{7}$ Same results even if less clear are obtained in [13] when analyzing the pad dynamics in the laboratory brake.
} 


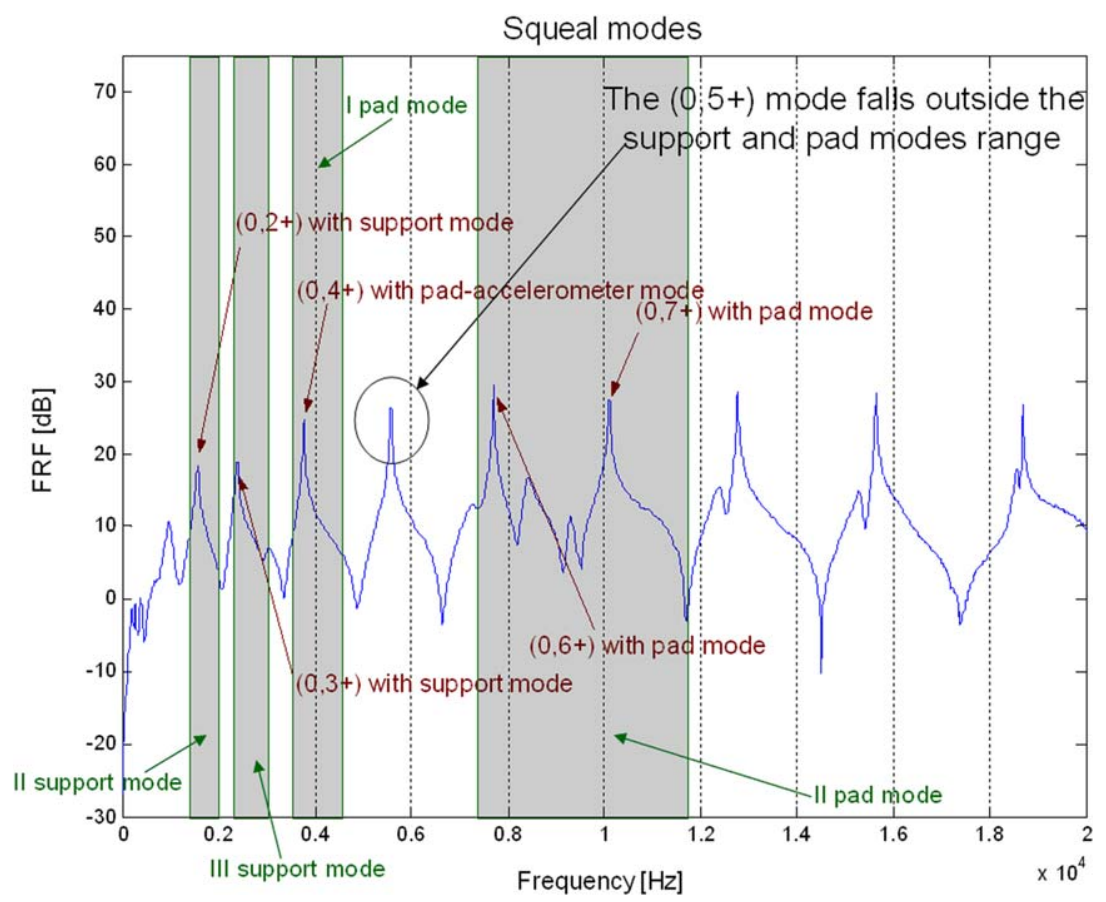

Fig. 8. Modes involved in squeal instabilities.

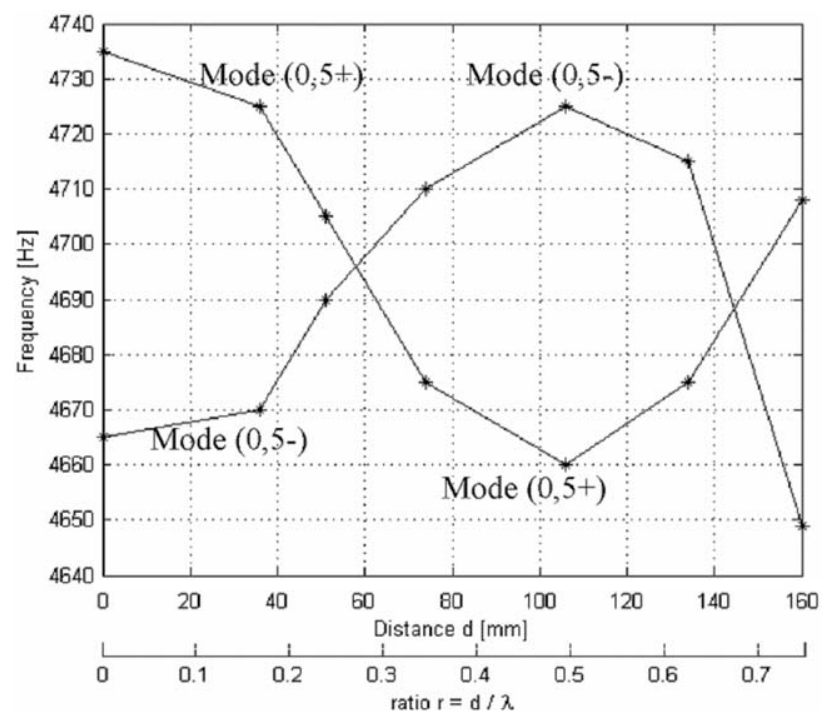

Fig. 9. Natural frequencies of the $(0,5)$ mode pair as the distance between pads changes.

Considering one pair of rotor double modes (e.g. mode (0,5) in Fig. 9), it is seen that as the distance between the pads changes, the frequency separation between the two natural frequencies oscillates.

If one introduces the ratio $r$ between $d$ and the circumferential wavelength of the mode shape $\lambda ; r=d / \lambda$, it is possible to see that the frequency separation is maximum when $r=0.5 i, i=0,1, \ldots, n$ and zero for $r=0.25+0.5 i$.

The modes involved in the squeal mechanism also depend on the value of $r$; the summary of results are given in Table 1. The table is divided into four regions, depending on the value of $r$. Squeals in zones A and C are characterized by a cosine squealing mode $\left(n, m^{+}\right)$, while in regions $\mathrm{B}$ and $\mathrm{D}$ the sine modes $(n, m-)$ become unstable. This reflects a characteristic of the dynamic behaviour of the laboratory brake. In fact, for $0<r<0.25$ and $0.75<r<1.25$ the cosine modes are at higher frequencies than the respective sine modes.

Therefore, it is possible to generalize what was found with the beam on disc and the laboratory brake with small pads, by stating that, between the two split double modes of the disc, it is generally the mode at higher frequency that squeals. 
Table 1

Squeal occurrences during experiments on high-frequency squeal

\begin{tabular}{|c|c|c|c|c|c|c|c|c|c|}
\hline Mode & $\mathrm{D}=0$ & $\mathrm{D}=36$ & $D=42$ & $\mathrm{D}=51$ & $\mathrm{D}=74$ & $D=106$ & $\mathrm{D}=134$ & $\mathrm{D}=160$ & $D=168$ \\
\hline$(0,4)$ & & & & & $\mathrm{r}=0.29$ & & & & \\
\hline$(0,4+)$ & $\mathrm{r}=0$ & & & $\mathrm{r}=0.20$ & & & & & \\
\hline$(0,5)$ & & & & $\mathrm{r}=0.25$ & $r=0.36$ & $\mathrm{r}=0.50$ & & & \\
\hline$(0,5+)$ & $\mathrm{r}=0$ & 1 & & & & & & & \\
\hline$(0,6)$ & & & \multirow{2}{*}{$\begin{array}{c}\text { Rotating } \\
\mathrm{r}=0.25\end{array}$} & $r=0.30$ & $\mathrm{r}=0.43$ & $r=0.60$ & \multirow{2}{*}{$\begin{array}{c}\text { Rotating } \\
\mathrm{r}=0.75\end{array}$} & & 1 \\
\hline$(0,6+)$ & $\mathrm{r}=0$ & & & & & & & & \\
\hline$(0,7)$ & & \multirow{2}{*}{$\begin{array}{c}\text { Rotating } \\
\mathrm{r}=0.25\end{array}$} & $\mathrm{r}=0.29$ & & $\mathrm{r}=0.50$ & & & & \\
\hline$(0,7+)$ & $\mathrm{r}=0$ & & & & & $r=0.7$ & $r=0.87$ & & {$[=1.11$} \\
\hline$(0,8)$ & & $\mathrm{r}=0.28$ & $\mathrm{r}=0.33$ & $\mathrm{r}=0.40$ & $\mathrm{r}=0.57$ & \multirow{2}{*}{$\begin{array}{c}\text { Rotating } \\
\mathrm{r}=0.78\end{array}$} & & \multirow{2}{*}{$\begin{array}{c}\text { Rotating } \\
\mathrm{r}=1.27\end{array}$} & $\mathrm{r}=1.28$ \\
\hline$(0,8+)$ & $\mathrm{r}=0$ & & & & & & $\mathrm{r}-1$ & & \\
\hline$(0,9)$ & & & $\mathrm{r}=0.37$ & $r=0.45$ & & & & $\mathrm{r}=1.52$ & $\mathrm{r}=1.43$ \\
\hline$(0,9+)$ & $\mathrm{r}=0$ & & & & & $r=0.91$ & $\mathrm{I}=1.12$ & & \\
\hline
\end{tabular}

Moreover, another kind of squeal may develop at the boundaries between these zones. In fact, at the boundaries $(r=0.25, r=0.75$, and $r=1.25$ ), the two split modes coalesce so that both may squeal together, implying that the squeal deformed shape is no longer stationary, but rather the nodal lines rotate during a squeal period as predicted by several research studies (e.g. among the others by Ouyang et al. [38]) and as found in commercial brakes by Fieldhouse and Newcomb $[22,23]$.

The rotating squeal involves the mode $(0,6)$ for $r=0.25$, the mode $(0,7)$ for $r=0.25$, the mode $(0,6)$ for $r=0.75$, the mode $(0,8)$ for $r=0.78$, and the mode $(0,8)$ for $r=1.27$. Such behaviour has been clearly related to the system dynamics obtained for these values of $r$.

\subsection{Absence of stick-slip during squeal instability}

Another important finding obtained by using the laboratory brake [13] is the experimental evidence that stick-slip does not develop during squeal instability. These measurements are summarized in Fig. 10. The results show that the average velocity of the disc, ranging from 242 down to $42 \mathrm{~mm} / \mathrm{s}$ in seven steps (grey horizontal lines), is always higher than the maximum in-plane vibration velocity of the pad (black line).

The measurements also show that the vibration amplitude is not sensitive to speed variations of the disc beyond a certain value (above $200 \mathrm{~mm} / \mathrm{s}$ ). At lower speeds, below $60 \mathrm{~mm} / \mathrm{s}$, squeal disappears. In the range between 60 and $200 \mathrm{~mm} / \mathrm{s}$ the sound pressure amplitude decreases on decreasing the rotational speed of the disc.

Moreover, the absence of stick-slip behaviour corroborates the mode lock-in theory as a reliable explanation of the squeal instability.

\subsection{Tribological analysis of the contact surfaces}

The tribological analysis developed on the tribobrake by means of scanning electron microscope observations of the contact surfaces allows for a comparative investigation on the characteristics of the third body and surface topography under both silent and squealing conditions [31]. Due to the non-homogeneity of the pad material, only a limited fraction of the pad surface is in contact with the disc. This area of real contact is confined within a number of contact plateaus, where the local contact forces assume large values.

The same pad surface was analyzed after braking without squeal (Fig. 11a) and braking with squeal (Fig. 11b). The sliding surface after squeal is distinctly different from that without squeal. The former is characterized by exfoliations of friction material both at macro (covering large portions of the contact surface) and micro (involving the third body layer) scales, and by superficial cracks. The second is characterized by an abrasive wear topography.

In order to understand the role of the third body and the effective depth of the superficial cracks, the pad was cut in a direction normal to the friction surface. Fig. 11c shows an example of the profile of the contact surface. It can be observed that the cracks also propagate to the internal part of the friction pad, in proximity with the contact surface. The exfoliations of friction material are either due to detachment of the third body or, sometimes, to the detachment of a superficial layer of the first body (pad). The same analysis carried out on the friction pad after braking without squeal reveals no cracks in the material, and the third body is attached to the surface of the first body. 


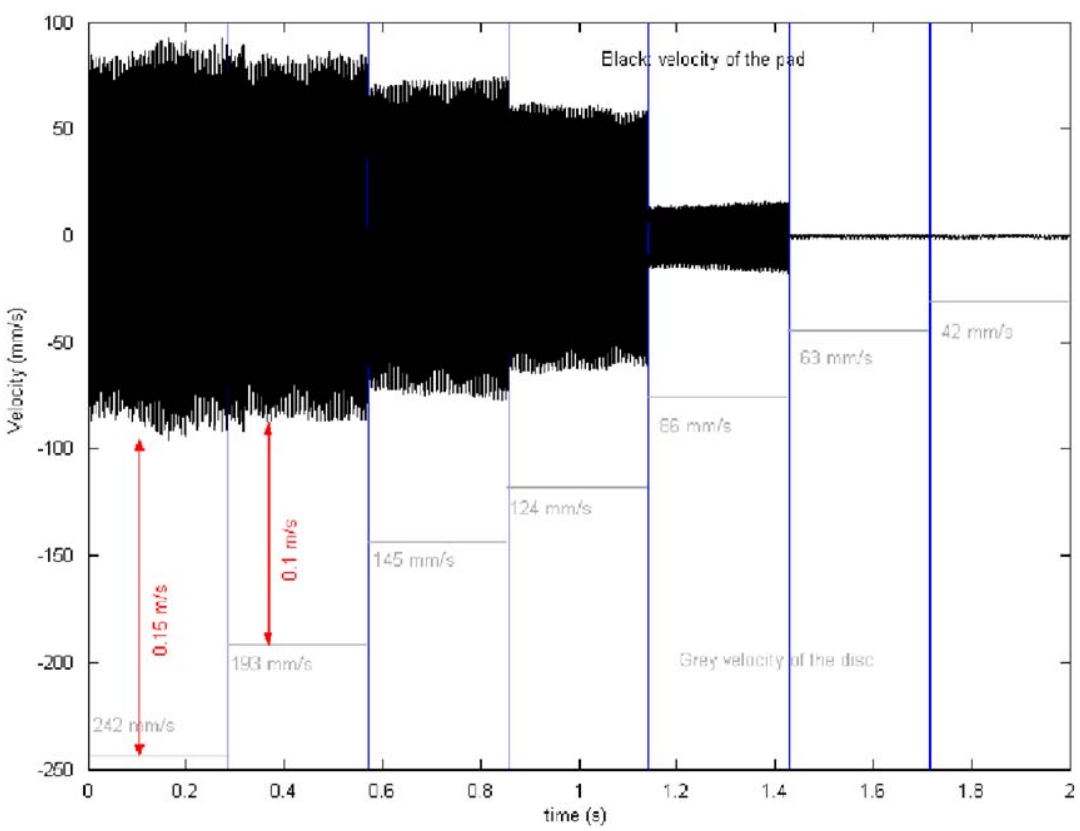

Fig. 10. Relative velocity between disc and pad and squeal vibration amplitude.

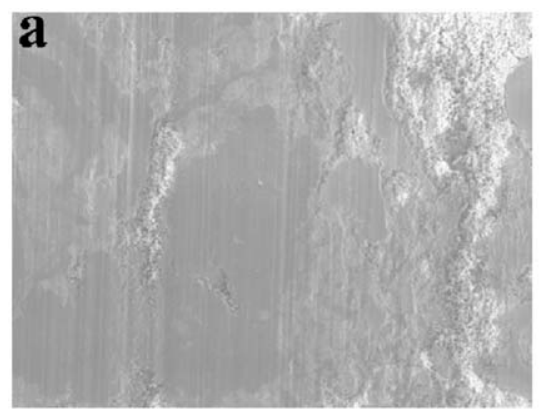

$300 \mu \mathrm{m}$

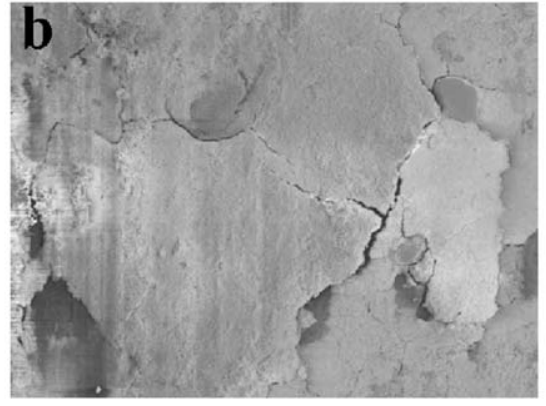

$800 \mu \mathrm{m}$

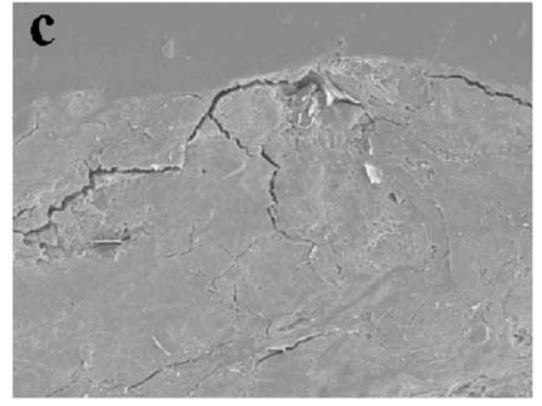

$50 \mu \mathrm{m}$

Fig. 11. (a) Friction surface without squeal, (b) friction surface after squeal, and (c) cut of the pad normal to the friction surface, after squeal.

The analysis of the surface topography highlights the presence of oscillations in the contact forces with consequent internal and superficial cracks of the pad material because of fatigue. In fact, the tangential bending modes of the pad or support have both normal and tangential components to the disc surface, inducing periodic shear and compression stress into the friction material at the squeal frequency.

\subsection{Effect of damping on brake squeal instability}

The beam-on-disc set-up was also used to characterize the effect of damping on squeal propensity. An extensive presentation of these experiments can be found in [10].

In order to conduct this study, damping material added along the external circumference of the disc (Fig. 12a) or along the beam (Fig. 12b) allows us to modify separately the value of the structural damping related to the two substructures, and thus the damping values of the two locking-in modes.

Four cases are studied and presented hereafter:

- Case A. Naturally damped system: no damping layer are used.

- Case B. One damping layer added to the disc.

- Case C. One damping layer added to the beam. 

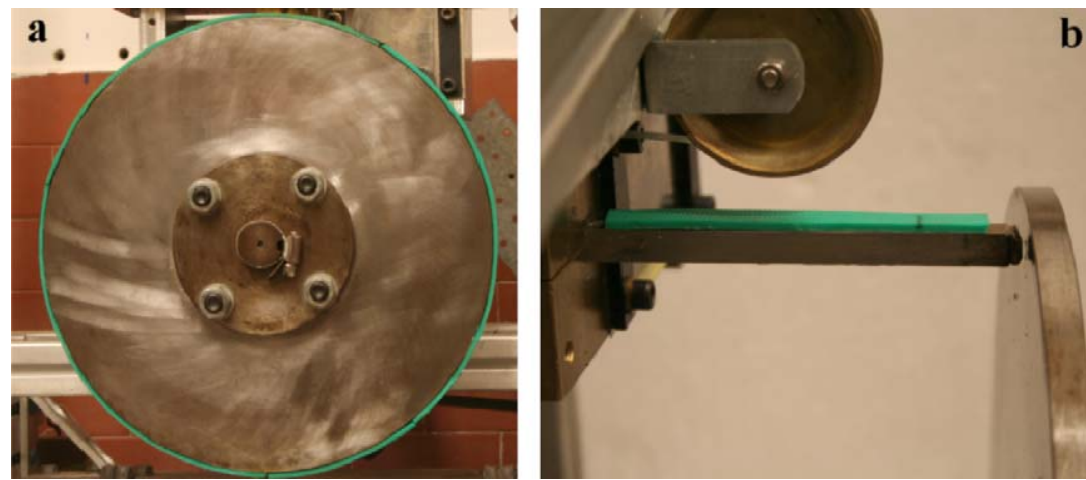

Fig. 12. Addition of layers of damping material: (a) on the disc and (b) on the beam.

Table 2

Modal damping of the beam and disc mode for different configurations.

\begin{tabular}{ll}
\hline Disc configuration & Modal damping of the disc mode (\%) \\
\hline Disc without damping layer & 0.48 \\
Disc with damping layer & 1.45 \\
& \\
Beam configuration & Modal damping of the beam mode (\%) \\
\hline Beam without damping layer & 2.50 \\
Beam with 1 damping layer & 3.70 \\
Beam with 2 damping layers & 5.70 \\
\hline
\end{tabular}

- Case D. Two damping layers added to the beam.

- Case E. One damping layer added to the beam and one damping layer added to the disc.

Table 2 shows the modal damping of the disc and the beam modes calculated for different configurations of the set-up.

The propensity of the system to squeal is measured through the experimental lock-in plots and the range of the system parameter for which squeal develops is used as the measure of the squeal propensity.

In order to obtain such lock-in plots the frequency of one of the coalescing modes must be varied in a controlled way; thus, small masses are added to the beam at steps of $3 \mathrm{~g}$ and the natural frequencies of the two coalescing modes are measured from the PSD of the acceleration signals of either the beam or the disc (Figs. 13b and c).

The measure of the unstable range is then presented in terms of intervals of both the added mass and the beam's natural frequency, between the lock-in and the lock-out points.

The first set of tests is performed on the beam-on-disc without the addition of damping materials (case A). The damping coefficient of the second mode of the beam is $2.5 \%$, while the damping of the $(0,4)$ mode of the disc is $0.48 \%$. Fig. 13 a shows the behaviour of the system natural frequencies, calculated during the braking phase as a function of the value of the added mass. In this case the mass is ranged between 0 and $33 \mathrm{~g}$ to shift the natural frequency of the beam from $2800 \mathrm{to} 2370 \mathrm{~Hz}$. When $17 \mathrm{~g}$ are attached, the mode of the beam coalesces with the $(0,4)$ mode of the disc, and squeal vibration and noise (over $100 \mathrm{~dB}$ ) appear. This point is labeled as the lock-in point.

By increasing the attached mass, the squeal occurs at every braking test at the coalescing frequency, which remains almost constant. Once the lock-out point is reached, the mode of the beam shifts to a frequency lower than that of the disc mode and the squeal disappears. The difference of added mass between the lock-in and lock-out points is, in this case, $9.7 \mathrm{~g}$.

The dynamics of the beam is varied by modifying the added mass. An increase of mass corresponds to a decrease of the natural frequencies of the beam. In order to generalize the obtained results, the range of instability can be compared by comparing the values of the natural frequencies of the beam (when not in contact with the disc) at the lock-in and lock-out point. The corresponding unstable frequency range is then $156 \mathrm{~Hz}$.

Seemingly, Figs. 14a-d present the lock-in graphs for the cases B-E. Table 3 lists the obtained results.

Table 3 shows the damping distribution, the ratio between the damping values and the frequency range of the beam mode that leads to squeal. From the comparison between case $\mathrm{A}$ and case $\mathrm{E}$ it can be asserted that a homogeneous increase of the modal damping of the two coalescing modes stabilizes the system by decreasing the unstable frequency range. 


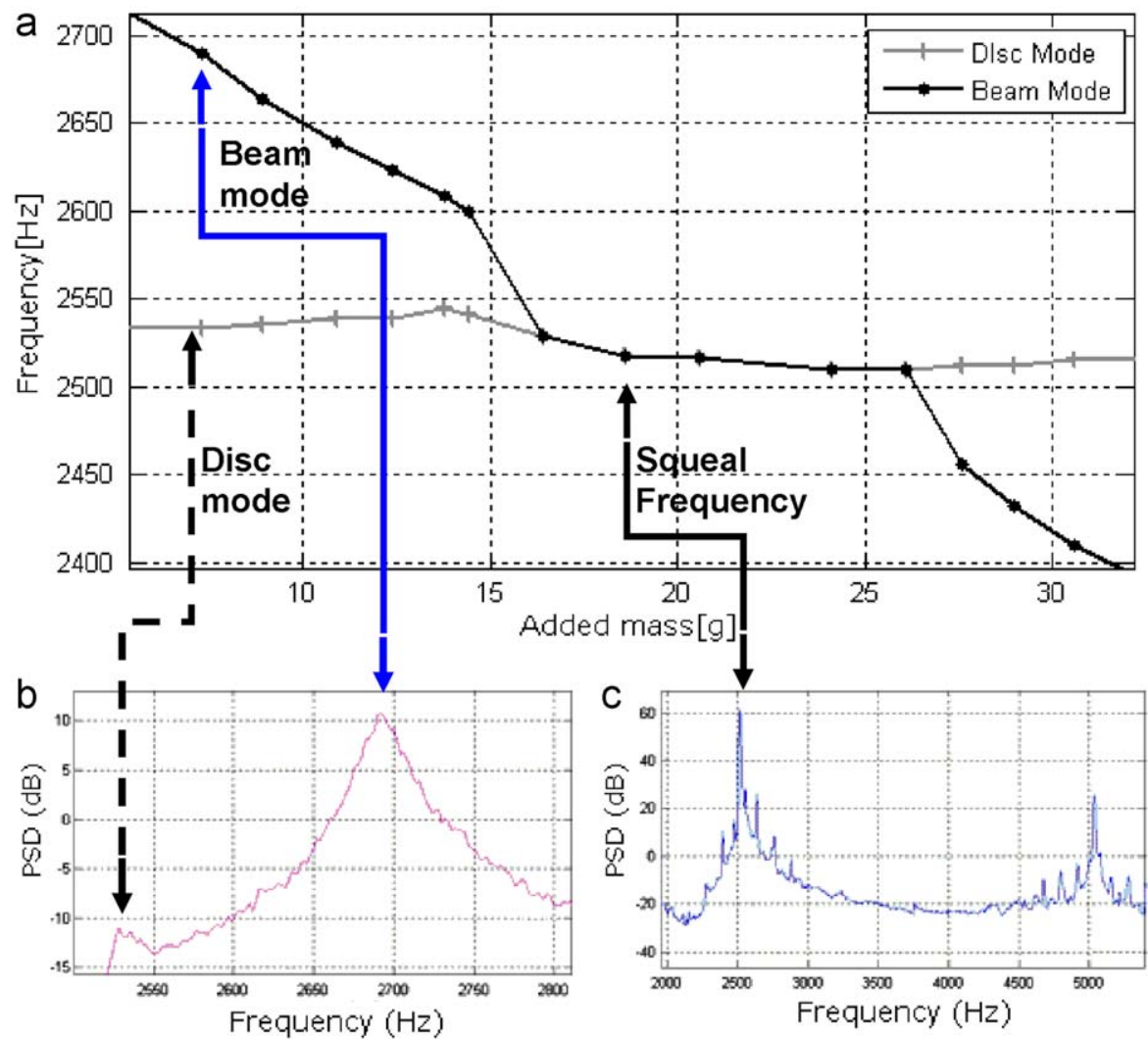

Fig. 13. Experimental evaluation of the lock-in plot for a system without damping layers.

Comparing the case $A$ with $C$ and $D$ it is evident that an increase of damping of the beam mode increases the difference between the damping of the two coalescing modes (larger damping ratio); the effect is a large increase of the unstable range of the system dynamics, from 150 up to $380 \mathrm{~Hz}$. On the contrary, going from case A to case B, only the disc damping is increased, the damping ratio decreases and, consequently, the unstable range decreases.

In conclusion, the results of the analysis indicate two different, almost opposite, effects due to the addition of damping material:

- a homogeneous increase of the structural damping of the system leads to a simultaneous increase of the modal damping of the coalescing modes, by lowering the system response and the propensity of the system to generate squeal;

- a non-homogeneous increase of the system damping, increasing the difference between the damping of the coalescing modes, can lead to an increase of the propensity of the system to squeal, especially if the damping is only added to the most damped mode.

These experimental results confirm the numerical analyses obtained in literature [39-42], highlighting the importance of the distribution of the structural damping in a brake apparatus.

\section{Models}

Given the simple geometry of the set-ups considered here. It is possible to develop consistent models using modal or FE approaches. These models can be either linear or nonlinear, taking into account contact stick and detachment, or the dependency of the friction coefficient on the relative velocity.

Theoretical models (viz., [6,38,43] ) are able to capture the squeal occurrence, but it is generally difficult to reproduce the dynamics of the system that depends on non-perfect boundary conditions. Thus, these models do not permit us to match exactly the experimental natural frequencies (and, therefore, squeal frequencies) and the theoretical ones. However, the correspondence between the unstable modes is usually satisfactory.

Reduced models, obtained through an experimental modal analysis provide good results in detecting the unstable frequencies through a complex eigenvalue analysis, but the implementation of nonlinear effects in these models is difficult and usually avoided. 


\section{a}

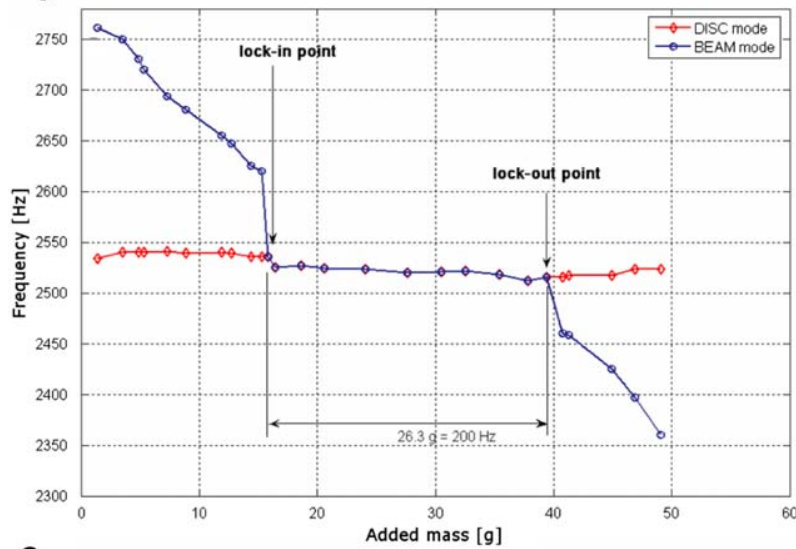

C

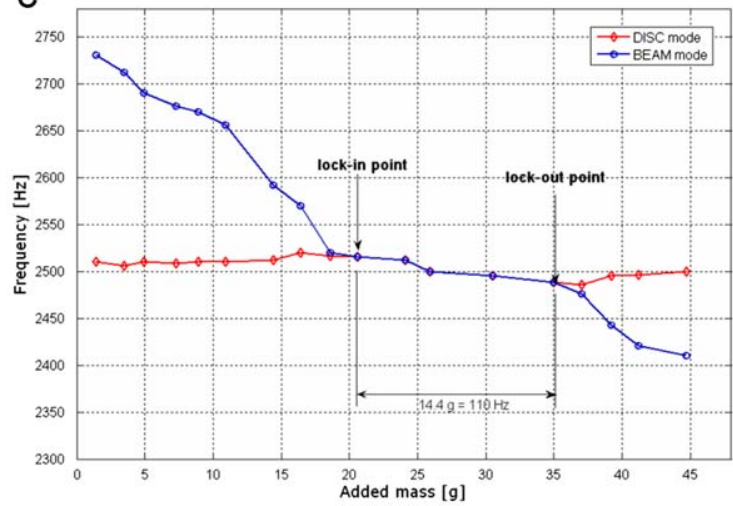

b

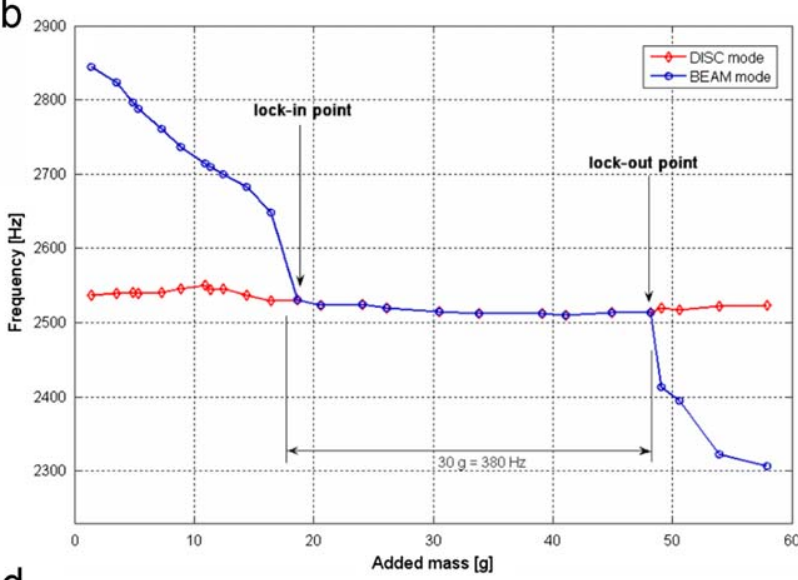

d

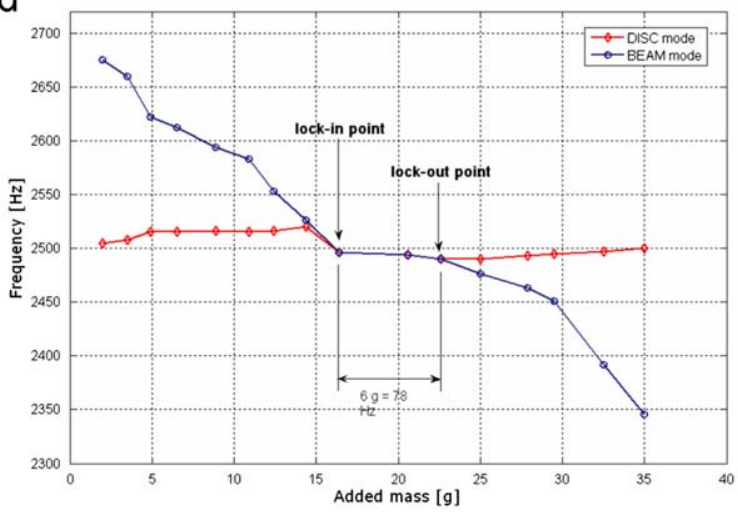

Fig. 14. Plot of the system instability (lock-in graphic) when one (a) and two (b) damping layers are applied to the beam and no damping layers are applied to the disc, (c) one damping layer added to the disc and none on the bream, and (d) one damping layer added to the disc and one added to the beam.

Table 3

Modal damping distribution and unstable frequency range for different configurations.

\begin{tabular}{|c|c|c|c|c|c|}
\hline \multicolumn{2}{|c|}{ Set-up configuration } & \multirow{2}{*}{$\begin{array}{l}\text { Damping of disc } \\
\text { mode }(\%)\end{array}$} & \multirow{2}{*}{$\begin{array}{l}\text { Damping of beam } \\
\text { mode (\%) }\end{array}$} & \multirow{2}{*}{$\begin{array}{l}\text { Damping ratio } \\
5.2\end{array}$} & \multirow{2}{*}{$\begin{array}{l}\text { Lock-in frequency } \\
\text { range }(\mathrm{Hz})\end{array}$} \\
\hline A & No damping layers & & & & \\
\hline $\mathrm{B}$ & Damping layer on the disc & 1.45 & 2.5 & 1.7 & 110 \\
\hline $\mathrm{C}$ & One damping layer on the beam & 0.48 & 3.7 & 7.7 & 200 \\
\hline $\mathrm{D}$ & Two damping layers on the beam & 0.48 & 5.7 & 11.8 & 380 \\
\hline $\mathrm{E}$ & $\begin{array}{l}\text { Damping layer on both the disc } \\
\text { and the beam }\end{array}$ & 1.45 & 3.7 & 2.6 & 80 \\
\hline
\end{tabular}

The FE models, after an updating phase, have a good correspondence with the experiments and are suitable for both linear and non-linear analyses. These models, however, are computationally expensive and may exhibit problems when dealing with the damping of different materials.

Reduced model are used by Tuchinda et al. [6,7] to predict the squeal instability in the beam on disc and by Giannini and Sestieri [14] for the laboratory brake. The first one used modal parameters derived from a FE description of the rotor, while the second performed an experimental modal analysis of the laboratory brake to obtain the dynamical description of the beams and the disc. In both models the dof were the modal coordinates of the rotor and the beam computed in free conditions (i.e. when they are not in contact with one another). The contact was indeed implemented through non-symmetric terms in the stiffness matrix, leading, in this way, to a linear model that has a homogeneous form.

Allgaier et al. [8] and Allgaier [9], on the contrary, describe the beam-on-disc set-up by a FE nonlinear model. Nonlinearities are due to the contact law, which depends on both the contact pressure and the relative velocity. For a given 
Table 4

Comparison between experimental and simulated results for the laboratory brake.

\begin{tabular}{lcc}
\hline Squealing mode & Squeal frequency_experimental $(\mathrm{Hz})$ & Squeal frequency-red. model (Hz) \\
\hline$(0,3+)$ Disc & 2005 & 2100 \\
$(0,4+)$ Disc & 3100 & 3150 \\
$3^{\text {rd }}$ Beam & 4300 & 4400 \\
$(0,5+)$ Disc & 4700 & 4900 \\
$(0,6+)$ Disc & 6400 & 6550 \\
$(0,7+)$ Disc & 8400 & 8450 \\
$5^{\text {th }}$ Beam & 9489 & 9600 \\
$(0,8+)$ Disc & 10,400 & Not predicted \\
$(0,9+)$ Disc & 12,400 & Not predicted \\
\hline
\end{tabular}

a The last two squeal condition are not predicted by the model because mode 0.8 and mode 0.9 are not included as the upper frequency limit during the EMA was $10 \mathrm{kHz}$.

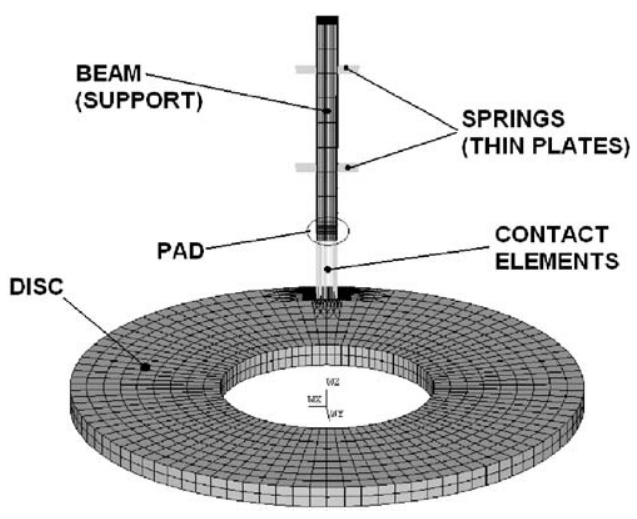

Fig. 15. FE model of the set-up.

normal pressure and a given rotational velocity of the rotor, the model can be linearized and the stability of the linearized model is studied.

Given their linearity, the complex eigenvalues analysis can easily detect the stability of these models; the eigenvalues with positive real part are equated to the squealing modes.

The comparison between the unstable eigenvalues and the experimental squealing modes is generally satisfactory. Table 4 presents such a comparison for the laboratory brake [14], showing how squeal frequency and squealing deformed shape can be easily obtained from such analysis.

However, as noted earlier, the linear models cannot predict the severity of the squeal events and may lead to an overestimation on the number of instabilities.

It is important to notice that the results from these models corroborate the experimental findings:

- The experimental correspondence of squeal frequency and squealing deformed shaped of unstable mode can be considered a further proof of the lock-in as the cause of the squeal event.

- Numerical instabilities always occur when one mode (of the beam or the pad) that has a consistent in-plane deformation becomes close to a mode (of the rotor) that has a consistent out-of-plane deformation. This fact corroborates the necessary role played by the in-plane dynamics of the pad in the instability mechanism.

Based on these results, Massi et al. [32] developed a novel numerical approach based on two different parallel analyses ${ }^{8}$ for the tribobrake:

- a linear FE model to predict the squeal conditions as a function of the main parameters;

- a non-linear FE model, that is able to reproduce the contact nonlinearities to obtain the time history of the brake system during squeal.

The former is preferable to conduct a parametric analysis at a low computing cost. The second is necessary to reproduce and analyze the contact surface behaviour under nonlinear conditions once squeal is developed.

\footnotetext{
${ }^{8}$ A similar approach is also used by Bakar and Ouyang for commercial brake FE models [45].
} 
a

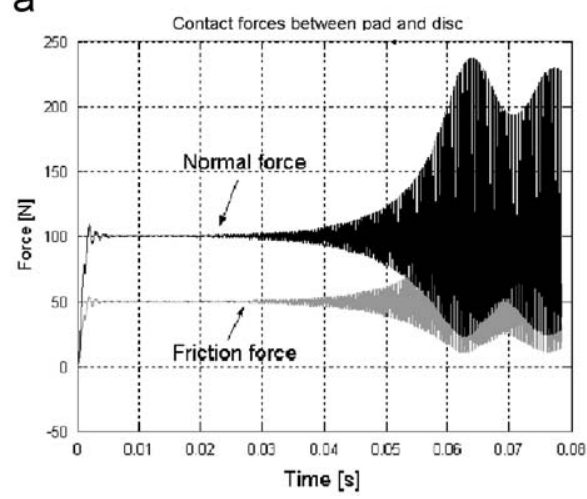

b

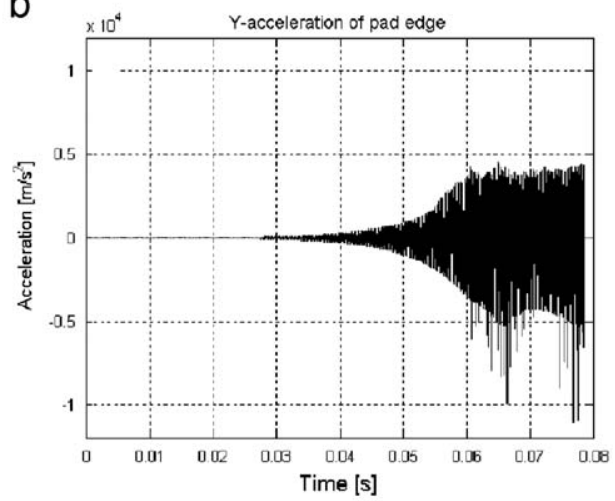

Fig. 16. Contact forces (a) and tangential acceleration of pad edge (b) for unstable behaviour at $3430 \mathrm{~Hz}$.

Fig. 15 shows the FE model of the set-up. The support of the pad is modelled by a beam. Four rows of springs, two on each side, hold the beam in the horizontal (friction force) direction, and model the four thin aluminium plates. A proportional structural damping is used for the entire model. Ansys ${ }^{\circledR}$ is used to investigate the dynamics of the system and to calculate its complex eigenvalues in function of the driving parameters. The contact elements are implemented in the FEM code using the MATRIX27 element, which produces an element stiffness matrix characterized by two nodes that can be non-symmetric. The complex eigenvalue analysis provides the tool to trace the regions of the parameter space that lead to instability, by predicting several unstable eigenvalues [32]. The values of the parameters that lead to instability are then introduced in the nonlinear model to reproduce the same instability.

The explicit dynamic three-dimensional FE code Plast3 [44] is used to simulate the nonlinear behaviour of the system in the time domain. This software uses a forward incremental Lagrange multiplier method, enabling the evaluation of the normal and tangential contact stresses in the contact region, as well as the determination of whether the contact surfaces stick, slide, or separate locally.

Figs. $16 \mathrm{a}$ and b show an unstable state leading to a limit cycle, with strong vibration of the system. After the contact forces reach the threshold value $(100 \mathrm{~N})$, a strong oscillation with exponential growth starts and develops until it reaches the limit cycle. The oscillations of both the contact force and the acceleration are harmonic, with the main harmonic coincident with the unstable frequency predicted by the linear model. Moreover, the exponential growth leading to a limit cycle agrees with the squeal behaviour observed during the experiments [31]. Thus, by introducing just the nonlinearities due to the contact, the characteristic trend of the squeal vibrations is well simulated.

Fig. 17 shows the local contact forces at five different time steps during the braking simulation. The time steps are chosen to cover one period of vibration. The white area indicates the local detachment between pad and disc surface. The black area corresponds to the maximum of the contact pressure. The last graphic in Fig. 17 shows the pressure distribution at the inner ray corresponding to the five time steps.

The oscillation of the local contact pressure between the leading and trailing edges of the pad is due to the component of the bending deformation of the support along the normal direction. This local oscillation represents a reliable "feedback mechanism" dependent neither on the velocity nor on the friction coefficient, and directly related to the deformed shapes of the unstable modes predicted by the eigenvalue extraction.

\section{Summary of the main results}

The beam-on-disc rig provides a wide range of repeatable sets of data correlating the dynamic characteristics of the setup with the squeal occurrence and a good experimental basis for the lock-in theory. Some mode lock-in characteristics are found and such characteristics can be reproduced by either linear or non-linear models. These characteristics are:

- The contact between the beam and the disc causes splitting of modes into two different frequencies. Lock-in tends to occur near the frequencies of the split cosine mode (the higher frequency one)

- The mode lock-in response occurs easily when the natural frequencies of the disc and the beam are close to one another. The occurrence rate of lock-in depends on how close the subsystem frequencies are.

- Both the theoretical and numerical models are suitable to predict the squeal frequencies, provided that one has a good updated model;

The main result obtained using the laboratory brake is the possibility of developing a simple model able to predict all, and only, the squeal frequencies that occur during the experiments. Yet the experimental set-up is much more complex and resembles a real brake more than the beam-on-disc set-up. 
Normal force distribution at the contact surface at five time steps for squeal at $3430 \mathrm{~Hz}$

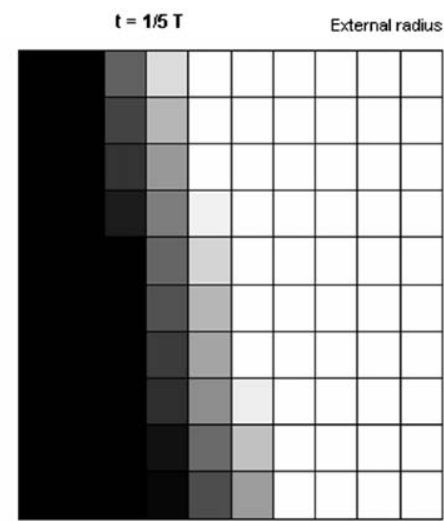

DISC VELOCITY

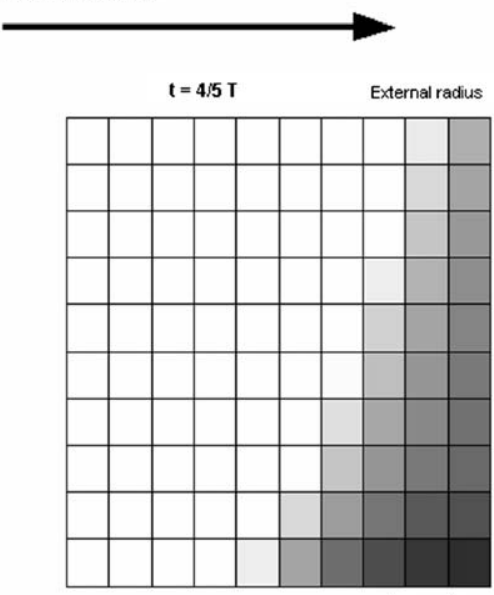

Inner radius

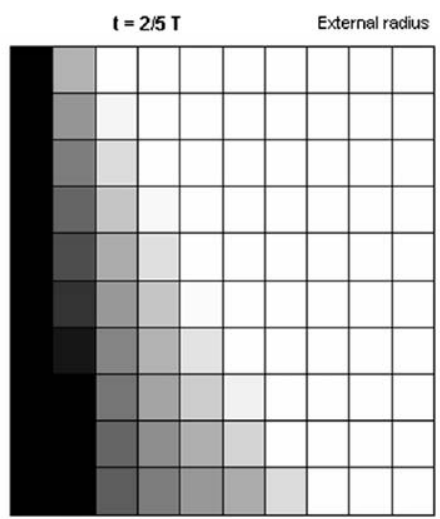

Inner radius

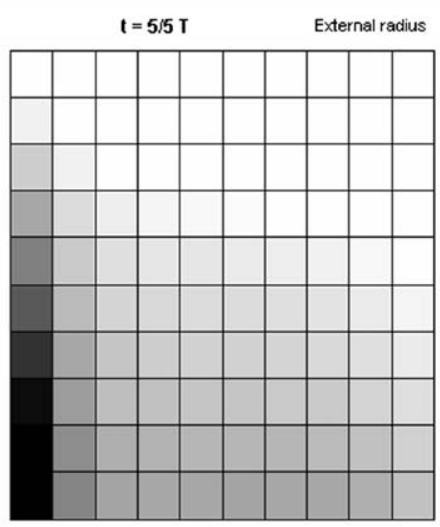

Inner radius

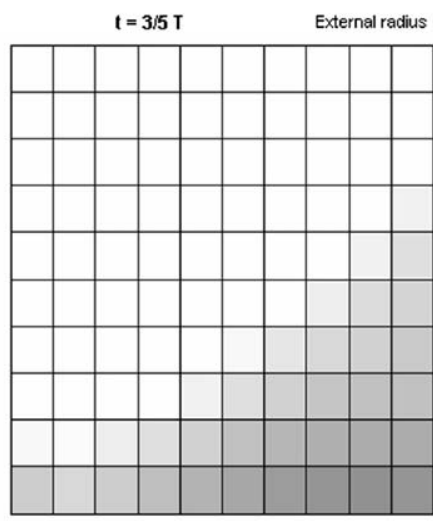

Inner radius

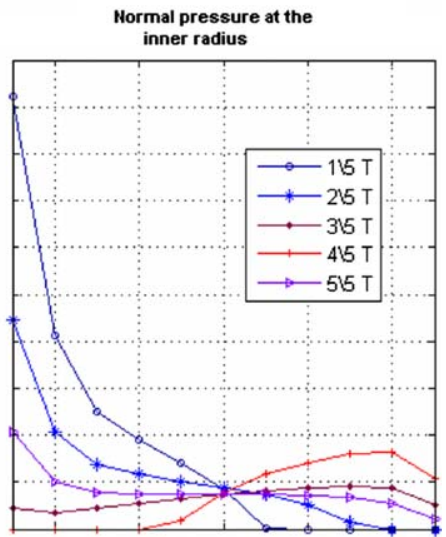

Fig. 17. Local contact pressure distribution during instability calculated for five time steps of the squeal limit cycle $(T=(1 / 3430) s)$, and contact pressure at the inner ray.

The onset of instability and several other aspects of the squeal vibrations can be obtained from a linear model of the brake. Therefore, it is possible to state that the non-linear aspects related to the contact between disc and pad, e.g. nonconstant friction coefficient, stick-slip or detachments, material nonlinearities, etc., do not cause squeal occurrence. On the contrary, the nonlinear aspects are probably the mechanisms that can stabilize the squeal vibrations on a limit cycle.

The design of the tribobrake, together with the dynamic and tribological analysis, permitted us to observe the following characteristics of the squeal instability:

- The lock-in condition between a pair of tangential and normal modes of the subsystems is the necessary condition for squeal.

- Squeal starts and can be predicted under linear conditions. However, in order to predict the squeal amplitude, a nonlinear model that considers local detachments must be used.

- The numerical analysis relates the oscillation of the local contact forces with the actual deformation of the system (modal coupling);

- The experimental data confirm the results of the simulations of the nonlinear FEM and allow us to give an interpretation of the fatigue damages revealed by the characteristic topography of the contact surfaces after squeal. Moreover the experiments point out a further problem concerning the life time of the pads related to the squeal vibrations.

\section{Conclusion}

Brake noise continues to be a long-standing problem for consumers and manufacturers alike. Notwithstanding the broad interest and attention devoted to the problem for many years, only recently some understanding of the different types of brake noise has become available, particularly squeal at low and high frequencies, which is generally considered 
the most critical. Also, the different mechanisms of squeal emission are now generally accepted and the theory of mode lock-in has become more accepted in the technical community. In the authors' opinion these advances should be mostly ascribed to the increasing use of simplified test rigs that, since the 1990s have been extensively used to understand the causes of the squeal phenomenon. These simplified laboratory brakes permitted production of repeatable squeal conditions and, consequently the construction of appropriate models that explain why and when a brake squeals. In parallel considerable effort was made using complex FE models applied to the laboratory brakes which verified at least qualitatively, the results of the simplified models.

In this paper, three simplified test rigs are considered: the beam on disc, the laboratory brake, and the tribobrake COLRIS. All the numerical and experimental results related to these test rigs agree and can be linked together to highlight that squeal is a dynamic instability driven by three factors:

1. The friction force that induces asymmetry in the stiffness matrix. This is a characteristic exhibited by any friction law because friction couples together normal and tangential forces.

2. The lock-in between two modes that are close in frequency and characterized by a phase difference [13,33] close to $90^{\circ}$. The two modes must have (usually the disc) a large out-of-plane displacement in the contact point, the other (the beam in beam on disc, the pad in the laboratory brake, or either of them in the tribobrake) a large modal displacement in the tangential direction. The resonance of the latter is essential since it induces $90^{\circ}$ phase shift between the friction force and the displacement of the pad. Moreover, the increase of damping of the coalescing modes may increase the frequency range for which such a $90^{\circ}$ phase shift occurs, leading to a wider unstable range.

3. The feedback force couples the in-plane vibration of the pad with the bending modes of the disc and the beams. This force is in phase with the displacement of the pad; thus, it has a $90^{\circ}$ phase difference with respect to the out-of-plane displacement of the disc or the beams. The feedback force can be caused by the misalignment angle of the beam (beam on disc and laboratory brake) as well as a specific mode of the pad or of the support in the tribobrake.

To conclude, a squeal-free design of a brake system should consider not only the out-of plane dynamics but also the inplane dynamics, especially of the pad; moreover, the role of damping must be thoroughly considered because experimental evidence shows that by neglecting damping one may underestimate the squeal propensity of the brake system. Finally, Stick-slip, detachment between disc and pad, and other nonlinear characteristic of the brake do not affect squeal propensity of the brake but play a relevant role on the amplitude of the squeal limit cycle and therefore on the amplitude of the radiated sound.

\section{Acknowledgments}

The authors wish to thank Mr. Zhaoshun Xu, who contributed significantly to the research developed at CMU.

\section{References}

[1] A. Akay, Acoustics of friction, Journal of the Acoustic Society of America 111 (2002) 1525-1548.

[2] N.M. Kinkaid, O.M. O’Reilly, P. Papadopoulos, Automotive disc brake squeal, Journal of Sound and Vibration 267 (2003) $105-166$.

[3] S.W.E. Earles, G.B. Soar, Squeal noise in disc brakes, in: Proceedings of the Vibration and Noise in Motor Vehicles Conference, Institution of Mechanical Engineers, 1971, pp. 61-69, Paper Number C 101/71.

[4] S.W.E. Earles, A mechanism of disc-brake squeal, Technical Report 770181, SAE, Warrendale, PA, 1977.

[5] A. Akay, J. Wickert, Z. Xu, Investigation of mode lock-in and friction interface, Final Report, Department of Mechanical Engineering, Carnegie Mellon University, 2000.

[6] A. Tuchinda, N.P. Hoffmann, D.J. Ewins, W. Keiper, Effect of pin finite width on instability of pin-on-disc systems, in: Proceedings of IMAC XX, 2002.

[7] A. Tuchinda, N.P. Hoffmann, D.J. Ewins, W. Keiper, Mode lock-in characteristics and instability study of the pin-on-disc system, in: Proceedings of IMAC XIX, 2001.

[8] R. Allgaier, L. Gaul, W. Keiper, K. Willnery, N. Hoffmann, A study on brake squeal using a beam on disc, in: Proceedings of IMAC XX, 2002.

[9] R. Allgaier, Experimentelle und numerische untersuchungen zum bremsenquietschen, Ph.D. Thesis, University of Stuttgart., 2004.

[10] F. Massi, O. Giannini, Effect of damping on the propensity of squeal instability: an experimental investigation, Journal of the Acoustical Society of America 123 (4) (2008).

[11] O. Giannini, A. Akay, A laboratory brake for the study of automotive brake, in: Proceedings of IMAC XX, 2002.

[12] O. Giannini, Experiments and modelling of squeal noise on a laboratory disc brake, Ph.D. Thesis, University of Rome "La Sapienza," 2004.

[13] O. Giannini, A. Akay, F. Massi, Experimental analysis of brake squeal noise on a laboratory brake set-up, Journal of Sound and Vibration 292 (2006) $1-20$.

[14] O. Giannini, A. Sestieri, Predictive model of squeal noise occurring on a laboratory brake, Journal of Sound and Vibration 296 (2006) 583-601.

[15] O. Giannini, F. Massi, A. Sestieri, Experimental characterization of the high frequency squeal on a laboratory brake set-up, in: Proceedings of IMAC XXIII, 2005

[16] O. Giannini, F. Massi, An experimental study on the brake squeal noise, in: Proceedings of ISMA 2004.

[17] F. Massi, O. Giannini, Extension of a modal instability theory to real brake systems, in: Proceedings of IMAC XXIII, 2005.

[18] O. Giannini, F. Massi, Characterization of the high frequency squeal on a laboratory brake set-up, Journal of Sound and Vibration 310 (1-2) (2008) 394-408.

[19] M.R. North, Disc brake squeal, a theoretical model, Technical Report 1972/5, Motor Industry Research Association, Warwickshire, England, 1972.

[20] M.R. North, Disc brake squeal, in: Proceedings of the Conference on Braking of Road Vehicles, Automobile Division, Institution of Mechanical Engineers, Mechanical Engineering Publications Limited, London, England, 1976, pp. 169-176.

[21] F. Massi, L. Baillet, O. Giannini, Experimental analysis on squeal modal instability, in: Proceedings of IMAC-XXIV, 2006. 
[22] J.D. Fieldhouse, P. Newcomb, The application of holographic interferometry to the study of disc brake noise, Technical Report 930805, SAE, Warrendale, PA, 1993.

[23] J.D. Fieldhouse, T.P. Newcomb, Double pulsed holography used to investigate noisy brakes, Optics and Lasers in Engineering 25 (6) (1996) $455-494$.

[24] S.K. Rhee, P.H.S. Tsang, Y.S. Wang, Friction-induced noise and vibration of disc brakes, Wear 133 (1989) 39-45.

[25] S.K. Rhee, M.G. Jacko, P.H.S. Tsang, The role of friction film in friction, wear, and noise of automotive brakes, Technical Report 900004, SAE, Warrendale, PA, 1990.

[26] M. Eriksson, F. Bergman, S. Jacobson, On the nature of tribological contact in automotive brakes, Wear 252 (2002) $26-36$.

[27] M. Eriksson, F. Bergman, S. Jacobson, Surface characteristic of brake pads after running under silent and squealing conditions, Wear 232 (1999) 621-628.

[28] F. Bergman, M. Eriksson, S. Jacobson, Influence of disc topography on generation of brake squeal, Wear 225-229 (1999) 621-628.

[29] G.X. Chen, Z. Zhou, P. Kapsa, L. Vincent, Experimental investigation into squeal under reciprocating sliding, Tribology 36 (2003) 961-971.

[30] G.X. Chen, Z. Zhou, P. Kapsa, L. Vincent, Effect of surface topography on formation of squeal under reciprocating sliding, Wear 253 (2002) $411-423$.

[31] F. Massi, Y. Berthier, L. Baillet, Contact surface topography and system dynamics of brake squeal, Wear 265 (11-12) (2008) 1784-1792.

[32] F. Massi, L. Baillet, O. Giannini, A. Sestieri, Brake squeal phenomenon: linear and non-linear numerical approach, Mechanical Systems and Signal Processing 21 (6) (2007) 2374-2393.

[33] F. Massi, O. Giannini, L. Baillet, Brake squeal as dynamic instability: an experimental investigation, Journal of the Acoustical Society of America 120 (3) (2006) 1388-1399.

[34] H.R. Mills, Brake squeak, Technical Report 9000 B, Institution of Automobile Engineers, 1938.

[35] R.T. Spurr, A theory of brake squeal, in: Proceedings of the Automobile Division, Institution of Mechanical Engineers, $1961-1962$, vol. 1, pp. 33-52.

[36] S.N. Chan, J.E. Mottershead, M.P. Cartmell, Parametric resonances at subcritical speeds in discs with rotating frictional loads, in: Proceedings of the Institution of Mechanical Engineers Part C, 1994, vol. 208(C6), pp. 417-425.

[37] O. Giannini, A. Sestieri, Sperimentazione e modellazione su un freno a disco da laboratorio per l'analisi del rumore di squeal, in: Proceedings of XVI Congresso dell'associazione Italiana di Meccanica Teorica ed Applicata AIMETA 2003, 9-12 settembre 2003, Ferrara, Italy.

[38] H. Ouyang, J.E. Mottershead, M.P. Cartmell, M.I. Friswell, Friction-induced parametric resonances in discs: effect of a negative friction-velocity relationship, Journal of Sound and Vibration 209 (2) (1998) 251-264

[39] P. Duffour, J. Woodhouse, Instability of systems with a frictional point contact. Part 1: basic modelling, Journal of Sound and Vibration 271 (2004) 365-390.

[40] N. Hoffmann, L. Gaul, Effect of damping on mode-coupling instability in friction induced oscillations, Zeitschrift Angewandte Mathematik und Mechanik 83 (8) (2003) 524-534.

[41] J.J. Sinou, L. Jèzèquel, Mode coupling instability in friction-induced vibrations and its dependency on system parameters including damping, European Journal of Mechanics A/Solids 26 (2007) 106-122.

[42] G. Fritz, J.J. Sinou, J.M. Dufal, L. Jèzèquel, Effects of damping on brake squeal coalescence patterns-application on a finite element model, Mechanics Research Communications 34 (2007) 181-190.

[43] J.E. Mottershead, Vibration- and friction-induced instability in disks, Shock and Vibration Digest 30 (1) (1998) $14-31$.

[44] L. Baillet, T. Sassi, Finite element method with Lagrange multipliers for contact problems with friction, Comptes Rendus de l'Académie des Sciences Paris, Series I 334 (2002) 917-922.

[45] A.R. Abu Bakar, H. Ouyang, Complex eigenvalue analysis and dynamic transient analysis in predicting disc brake squeal, International Journal of Vehicle Noise and Vibration 2 (3) (2006). 